\title{
Integrated water resources management using engineering measures
}

\author{
YAN HUANG \\ Changjiang Institute of Survey Planning Design and Research, Changjiang Water Resources Commission, No. 1863 \\ Jiefang Avenue, Wuhan, 430010 China \\ yhuang@cjwsjy.com.cn
}

\begin{abstract}
The management process of Integrated Water Resources Management (IWRM) consists of aspects of policies/strategies, measures (engineering measures and non-engineering measures) and organizational management structures, etc., among which engineering measures such as reservoirs, dikes, canals, etc., play the backbone that enables IWRM through redistribution and reallocation of water in time and space. Engineering measures are usually adopted for different objectives of water utilization and water disaster prevention, such as flood control and drought relief. The paper discusses the planning and implementation of engineering measures in IWRM of the Changjiang River, China. Planning and implementation practices of engineering measures for flood control and water utilization, etc., are presented. Operation practices of the Three Gorges Reservoir, particularly the development and application of regulation rules for flood management, power generation, water supply, ecosystem needs and sediment issues (e.g. erosion and siltation), are also presented. The experience obtained in the implementation of engineering measures in Changjiang River show that engineering measures are vital for IWRM. However, efforts should be made to deal with changes of the river system affected by the operation of engineering measures, in addition to escalatory development of new demands associated with socio-economic development.
\end{abstract}

\section{INTRODUCTION}

\subsection{Integrated Water Resources Management needs engineering measures}

Integrated water resources management (IWRM) is defined as "a process which promotes the coordinated development and management of water, land and related resources, in order to maximize the resultant economic and social welfare in an equitable manner without compromising the sustainability of vital ecosystems" (the Global Water Partnership (GWP)). From a management perspective, IWRM can be categorized into two types, i.e. integrated water utilization and disaster mitigation, the former involves hydropower, irrigation, navigation, water supply (domestic and industrial water use, etc.), and the latter involves mainly flood management and drought relief. To achieve those water management targets, engineering measures and non-engineering measures are planned and implemented.

Engineering (or structural) measures, such as dikes, pond, reservoirs, diversion channels, pumping stations, can reallocate water in terms of time and space, and are the operational tools to deal with water issues such as flood, drought and water pollution; complementarily, nonengineering (or non-structural) measures, such as data acquisition, hydro-meteorological forecasting, evacuation programmes and risk awareness education, are the means to ensure effective operation and use of engineering measures. Thus, in IWRM, a combination of engineering and non-engineering measures is commonly applied.

\subsection{Changjiang River and its water issues}

Changjiang River (Fig. 1) is the largest river in China. The river originates from the Qinghai-Tibet Plateau (elevation $5000 \mathrm{~m}$ ) and flows eastwards across China to reach the East Ocean at Shanghai estuary area. The river is $6300 \mathrm{~km}$ long and the basin is 1.8 million $\mathrm{km}^{2}$ in area $(18.8 \%$ of China's land area), involves 19 provinces of China, with an annual runoff of 960 billion $\mathrm{m}^{3}$. With such an abundant water volume, Changjiang River plays an important role in the socio-economic development of China. Of the Chinese population, 32.3\% live in this basin, which provides $32.5 \%$ of national food production and contributes $34 \%$ of the national GDP. It is the strategic water resource, hydropower development base and major inland navigation path (the so-called 'Golden Waterway') of China. Changjiang River is dominated by subtropical monsoon climate, while the upstream Qinghai-Tibetan Plateau area belongs to the plateau climate zone. The mean annual precipitation is about $1100 \mathrm{~mm}$, occurring mainly in the summer and autumn seasons. 


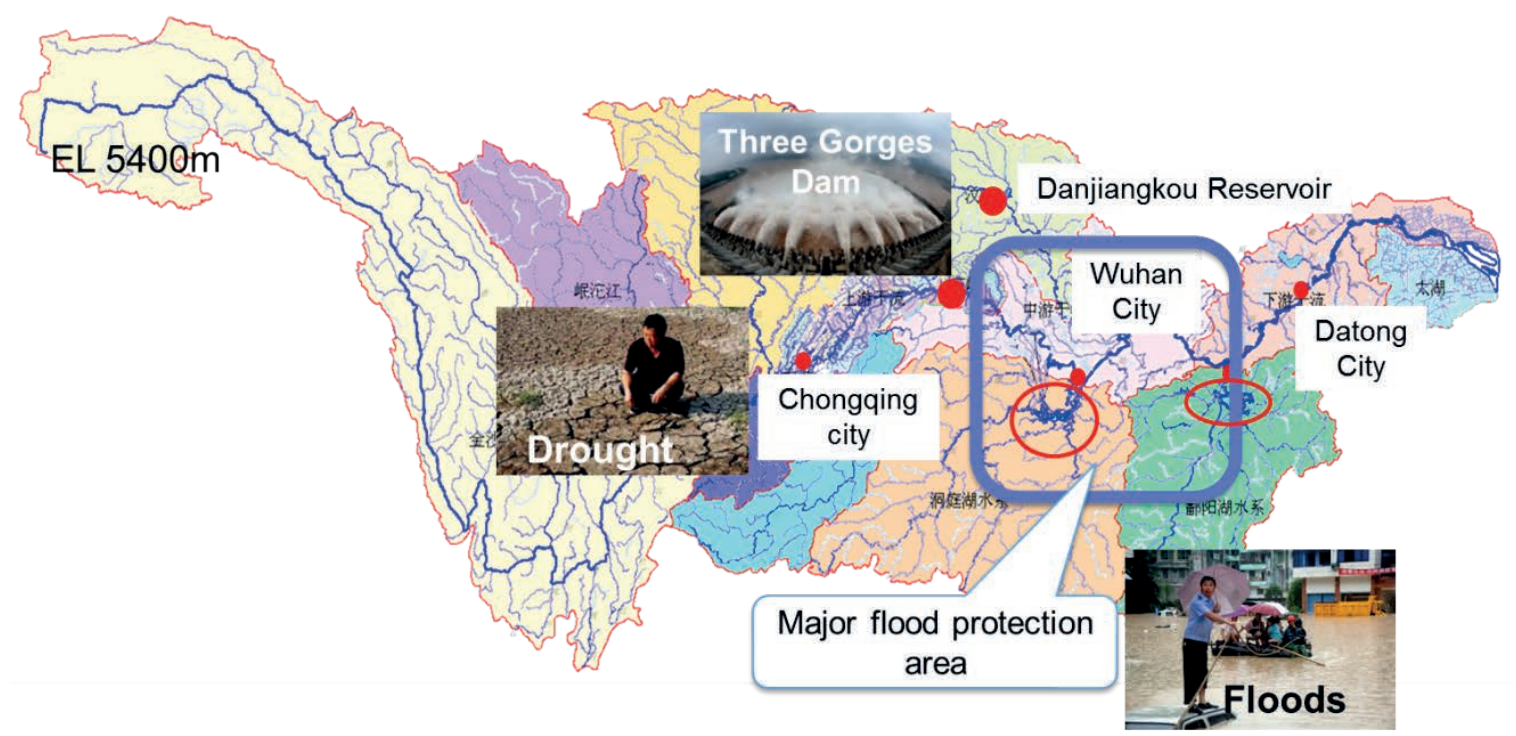

Fig. 1 Changjiang River basin. Water issues are droughts and floods in the upper reach; floods in the middle reach due to its low elevation and the sudden change from mountain areas to flood plains; and floods and navigation issues in the lower reach.

In a river as large as the Changiiang with complicated terrain and a typical monsoon climate, any water issue may occur. Amongst all types of water issues, flood receives the highest attention due to its relatively higher and frequent impacts. In this basin, floods occur very often and have caused much damage and loss to human life and the economy. For example, floods in 1931 and 1935 caused 142000 and 145000 deaths, respectively; in 1954, the basin-scale big floods which occurred from the upstream joined with floods in the mid-downstream areas, including Dongting Lake and Han River, and caused inundation of $31700 \mathrm{~km}^{2}$ farmland and killed more than 30000 people; in 1998, another basin-scale big flood occurred in Changjiang River, affecting 334 cities and towns, and killing 1562 people (CWRC 2003).

Due to the uneven distribution of precipitation, most of which occurs during the flooding season of May-September, drought also happens often in Changiiang River basin, being more severe in the upper area. For instance, in the drought during the dry season (spring) of 2006-2007, in Sichuan province and Chongqing city, 680 million people suffered from water shortage problems (CWRC 2011) and it affected $40000 \mathrm{~km}^{2}$ of farmland. In spring 2010, in five provinces, 510 million people suffered from water shortages, 214.8 million people lacked drinking water, and about $62500 \mathrm{~km}^{2}$ of farmland were affected. Associated with rapid economic development, water supply has become increasingly important.

\section{RIVER BASIN PLANNING}

In Changiiang River, in order to have a systematic, optimized and effective framework of engineering measures that can keep up with the socio-economic development change and needs, and provide strict constraints for land-use and other socio-economic development, an Integrated River Basin Management (IRBM) plan has been iteratively developed during the past decades. To date, there are three editions of the Changjiang River Basin Plan: the first was developed in 1959, the second in 1990, and the latest in 2012. On average the plan has been updated every 10-15 years. The following presents the framework and major outcomes of the plan, particularly engineering measures for IWRM/IRBM.

\subsection{Objective and framework of Changjiang River basin planning}

The objectives of the river basin planning are to:

- Improve the current flood management system, ensure flood safety; 
- Optimize water allocation, ensure water supply safety;

- Develop water resources exploration - increase hydropower capacity;

- Improve navigation capacity;

- Protect ecological and environmental status, ensure healthy river function;

- Improve basin-scale management, promote harmonic development.

The ultimate goal of developing river basin planning is to improve the capacity of the river basin to deal with water issues through implementation of engineering and non-engineering measures.

The integrated river basin planning consists of four major targets: (a) flood management and hazard mitigation, (b) integrated water resources utilization, (c) protection of the water resources environment and ecology, and (d) integrated basin management. For each target there are various means of achieving such planning targets resulting in various plans. For instance, for flood management and hazard mitigation, the means to achieve such targets include plans of flood control, waterlogging control and river regulation. Measures planned and proposed include both engineering and non-engineering ones. The planning framework is presented in Fig. 2.

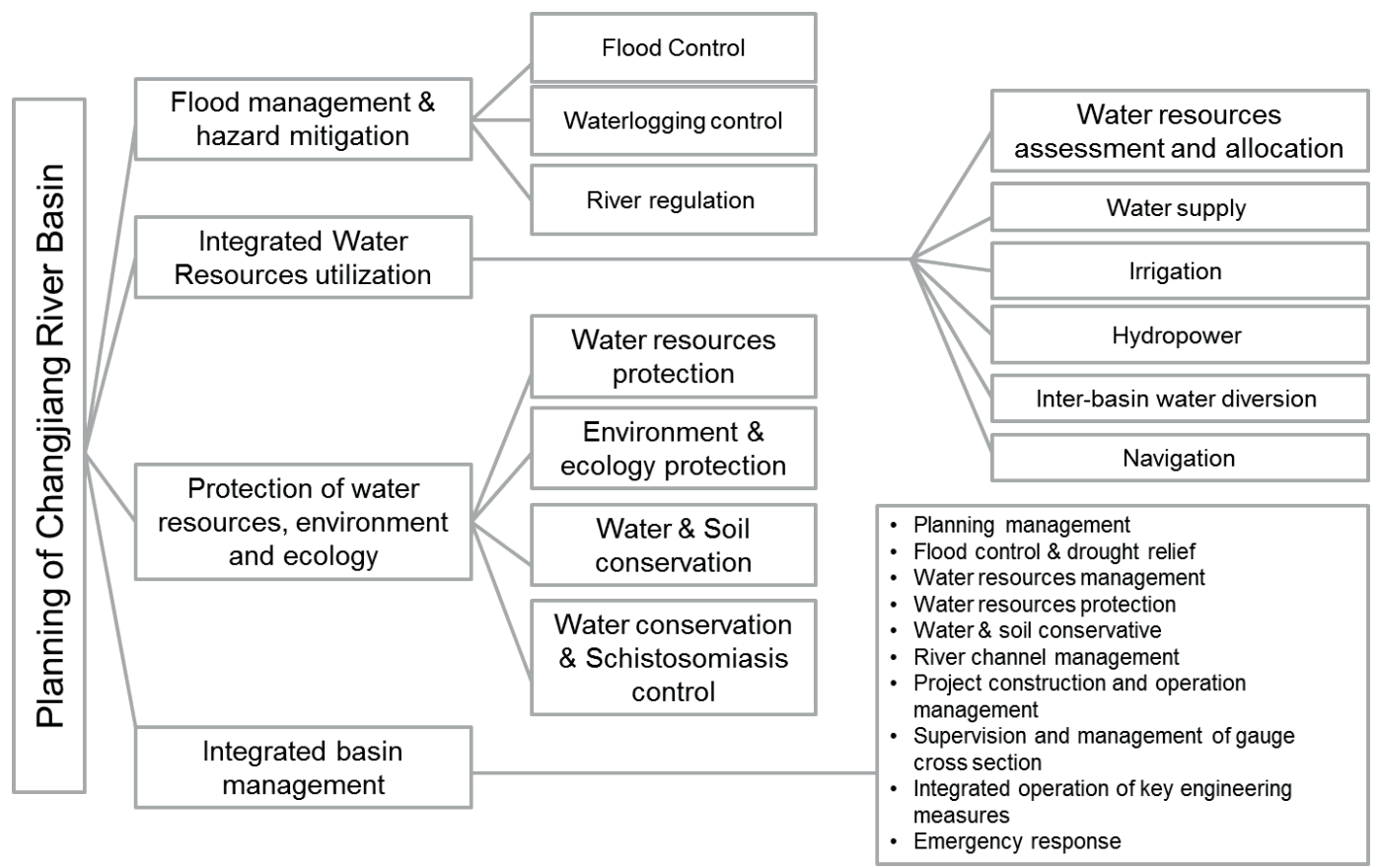

Fig. 2 Framework of river basin planning of Changjiang River basin.

\subsection{Planning of engineering measures}

The engineering measures are planned according to the water issues observed at certain areas in the river basin. The following sections present only major engineering measures developed in Changjiang River, including the targets of flood management and water utilization.

2.2.1 Flood management The major flooding problem is that, due to dense habitation that cannot be simply resolved by moving people away, there is a lack of discharge capacity for large floods. This issue is most severe in the middle-downstream area, i.e. the river reach between Yichang and Hankou stations (Fig. 1 shows their locations). In this reach, the flood discharge capacity of the river channel increases from $50000-60000 \mathrm{~m}^{3} / \mathrm{s}$ (Yichang) to $70000-80000 \mathrm{~m}^{3} / \mathrm{s}$ (Hankou); however, the floods which occur can easily exceed these values. For example, in 1931, 1935 and 1954, the flood discharge from the mainstream Changjiang River joined floodwaters from Dongting Lake and lateral runoff, so exceeding $100000 \mathrm{~m}^{3} / \mathrm{s}$. Thus, it is important to apply measures to complement the discharge capacity through water storage such as reservoirs, and 
retention zones etc. in addition to maintaining and enlarging the river channel discharge capacity through river regulation.

Following such criteria, and aiming particularly for the protection of the mid-downstream area, a systematic flood management system has been developed, in which the engineering measures consist of reservoirs in the upstream area, dikes and embankments in the mid-downstream area and retention zones in the downstream area, as shown in Fig. 3. In addition to the dikes, the plan provides total storage of 38 billion $\mathrm{m}^{3}$ and 100 billion $\mathrm{m}^{3}$ by reservoirs in the upstream (for the years 2015 and 2030, respectively), and 50 billion $\mathrm{m}^{3}$ storage by 40 retention zones. This measure will ensure that the water level for gauge stations (which are also very important cities/towns) of Shashi, Chenglingji, Hankou and Hukou will not exceed 45.0 m, 34.4 m, $29.73 \mathrm{~m}$ and $22.5 \mathrm{~m}$, respectively, corresponding to the 50 100 year return period safety level. These engineering measures provided flexibility and the backbone for flood management in Changjiang River.

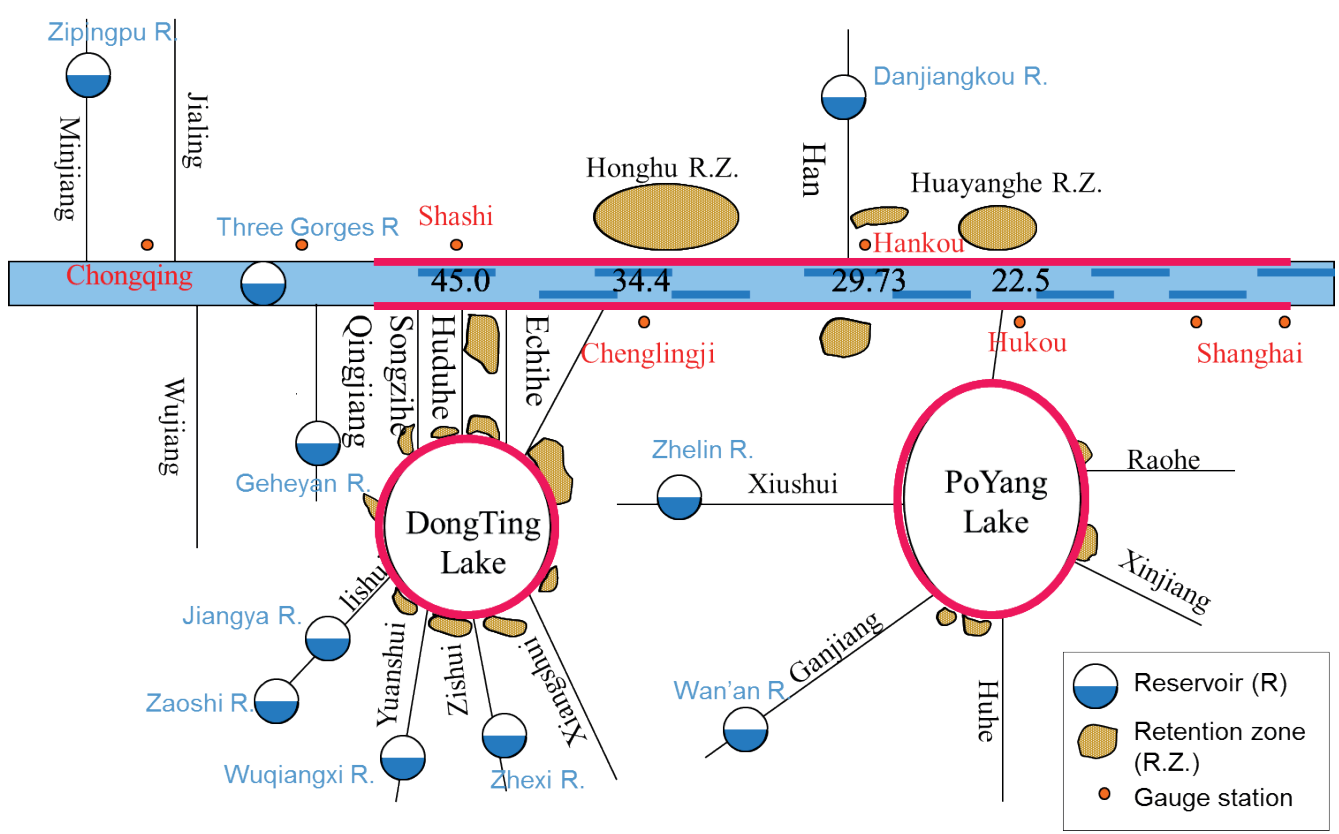

Fig. 3 Combination of engineering measures for flood management of Changjiang River.

2.2.2 Integrated water utilization After broad consultation and investigation, targets for water resources utilization are determined so as 'to control the total water use in river basin to not exceed 228.3 billion $\mathrm{m}^{3}$, with a development rate of $25 \%$ for the year of 2020; and to control the total water use in river basin to not exceed 234.8 billion $\mathrm{m}^{3}$, with a development rate of $30 \%$, for year 2030'. Aiming to achieve the development targets, the planning of integrated water utilization has been conducted through optimization of water allocation considering domestic and industrial water users, environmental flows, and inter-basin water division, etc., to improve water supply infrastructure with a water storage (reservoirs) and water distribution (channel, pumping systems, etc.) system. Based on the balance analysis of water supply and predicted water demands for each planning horizon $(2025,2035)$, engineering measures are planned for each area/region of the basin. For example, for the region of southwest Changjiang basin, the engineering measures planned consist of 2749 water storage projects (including 22 big reservoirs, 437 mid-sized reservoirs and 1251 small reservoirs), 326 water lift projects, 101 connection projects and 612 wells.

Planning of integrated water utilization also provides plans for hydropower, irrigation, navigation, etc. For hydropower development using engineering measures, a total installed capacity of $93300 \mathrm{MW}$ and $54010 \mathrm{MW}$ before 2020 and 2030, respectively, is planned. For the navigation development, plans for channel regulation and harbour construction, and stability control for the estuary area morphology are proposed, involving 54000 ha of land reclamation, $81 \mathrm{~km}$ utilization of beach area, and deepening of navigation channels at selected areas. 


\section{OPERATION AND BENEFITS OF ENGINEERING MEASURES}

\subsection{Reservoirs are very important engineering measures in IWRM}

Among all types of engineering measures, reservoirs can be regarded as the most integrated and complex, being used for multiple purposes including flood management, power generation, water supply and navigation. According to ICOLD (http://www.icold-cigb.org/GB/World_register/ general_synthesis.asp), worldwide there are two major categories of reservoir: single-purpose (28 640, 49.2\%) and multipurpose $(9812 ; 16.8 \%)$ reservoirs, which have significantly benefited socio-economic development.

\subsection{Operation of the Three Gorges Reservoir}

The Three Gorges Reservoir (TGR) has been in operation since 2003. The reservoir was originally developed with three objectives: flood control, power generation and navigation, in order of priority. Later, during the development of the operation regulations, the objective of compensating downstream low flow was introduced as another objective and has become more and more important due to the increasing attention and needs raised.

The key operation regulations for TGR are the regulation rules recently developed (CWRC 2009) which have been updated regularly. According to the regulation rules, the reservoirs shall keep the water level low at $145 \mathrm{~m}$ during the flooding season (10 June-15 September) to secure storage for flood management purposes; from 15 September the reservoir starts to impound water, and reaches the normal pool level of $175 \mathrm{~m}$ by the end of October; then the water level is maintained at a high level until the end of December, subject to the condition that discharge from the reservoir should maintain the navigation depth in the downstream area (indicated by a water level of $39.0 \mathrm{~m}$ at Miaozui station) as well as environmental flows (normally not less than $6000 \mathrm{~m}^{3} / \mathrm{s}$ ). The regulation rule is illustrated in Fig. 4 .

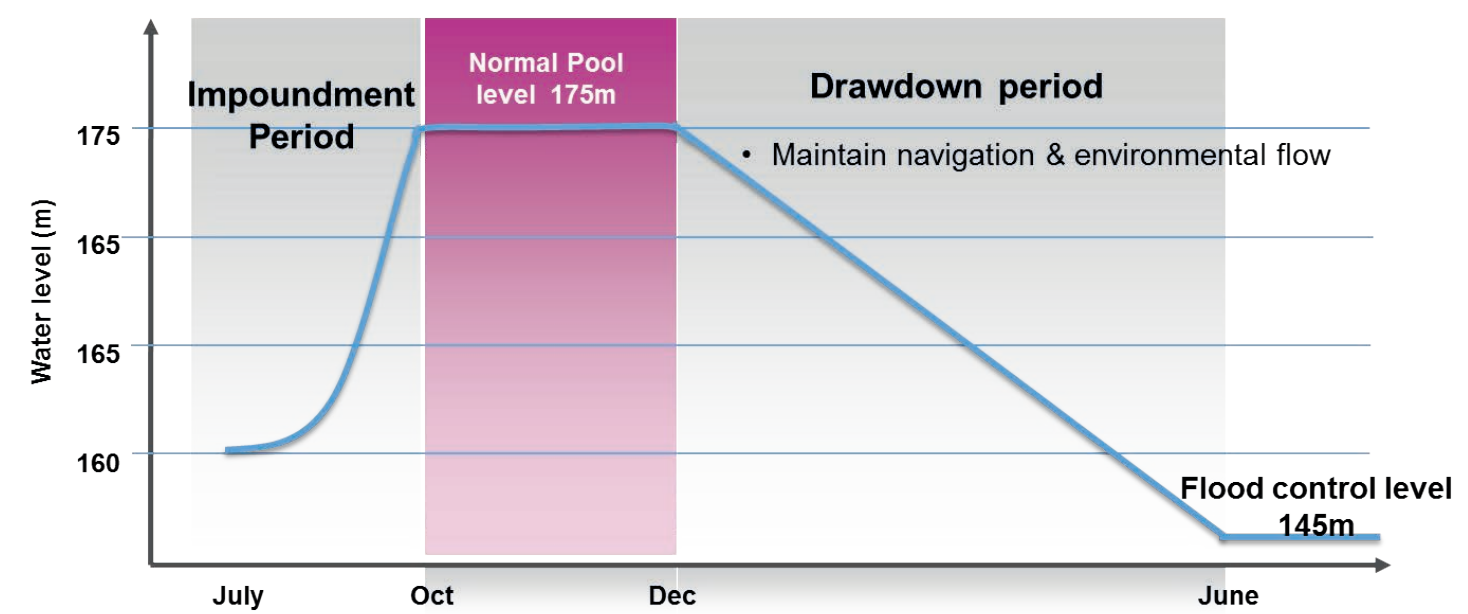

Fig. 4 Operation rules of the Three Gorges Reservoir for the hydrological circle year.

3.2.1 Flood management using the Three Gorges Reservoir As the backbone of flood management measures for the mid-downstream Changjiang basin, TGR provides enormous benefits to flood control for Changjiang River. Out of 39.3 billion $\mathrm{m}^{3}$ storage, 22.15 billion $\mathrm{m}^{3}$ is allocated for flood control, and the release capacity of the spillway of $102500 \mathrm{~m}^{3} / \mathrm{s}$. The operation of TGR, has improved the safety level of the Jingjiang reach downstream from 1 in 20 years to 1 in 100 years, and prevents devastating damage there by combining the use of retention basins for the case of floods of 100-1000 year frequency. In addition, it reduces the possibility of using retention basins near the Chenglingji area. To meet the storage demands for these objectives, the flood control storage is divided into three parts (Fig. 5): Part I from 145 to $155 \mathrm{~m}$ with storage of 5.65 billion $\mathrm{m}^{3}$, for flood protection of the Chenglingji area; Part II, 155-171 m with storage of 


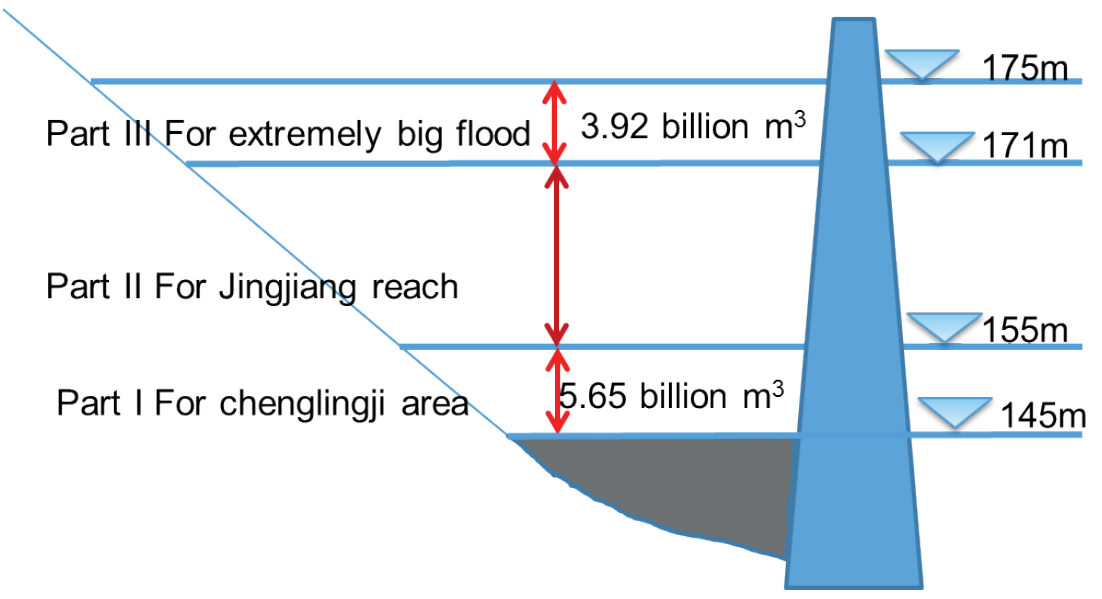

Fig. 5 Allocation of reservoir storage for flood control purposes for different areas downstream.

12.58 billion $\mathrm{m}^{3}$ for Jingjiang reach; and Part III, $171-175 \mathrm{~m}$, is for extremely large floods higher than the 100-year return period.

The TGR has significantly improved flood safety for areas downstream with its real-time operation. From 2008 till today, in the main channel particularly, the major flood protection targets of Jingjiang reach and Chenglingji area have not reached warning levels during flooding seasons. According to the statistics, for the year of 2010 alone, the benefits of flood management using TGR reached US\$ 4.5 billion.

In practice, however, it is difficult to strictly follow the regulation rules due to real situations. For example, due to the fact that in four branches at south Jingjiang reach in Hubei province dikes are currently under construction, so if discharge from TGR is larger than $45000 \mathrm{~m}^{3} / \mathrm{s}$ it might introduce risk at those areas; thus, since the flooding seasons of 2008 when TGR came into fullscale operation, until 2014, in real-time management, TGR minimized the flood risk by reducing flow discharge to the downstream taking into consideration such practical needs, with the result that almost no discharge has exceeded $45000 \mathrm{~m}^{3} / \mathrm{s}$ even when inflow exceeded $70000 \mathrm{~m}^{3} / \mathrm{s}$ in 2010.

3.2.2 Water compensation to downstream low flow Following the regulation rules, to compensate for low flow for irrigation, drinking and environmental flows, discharge from TGR shall not be less than $6000 \mathrm{~m}^{3} / \mathrm{s}$ during January-February, and about $57000 \mathrm{~m}^{3} / \mathrm{s}$ before May (to maintain the navigation depth downstream). During the 2010/2011 winter to spring perod, to deal with the drought that occurred in the mid-downstream area, jointly with TGR, reservoirs upstream have made compensation of 20 billion $\mathrm{m}^{3}$ of water.

3.2.3 Produce huge amount of power With the total installed capacity of $22500 \mathrm{MW}$ and designed annual power generation of 88 billion $\mathrm{kW}$, power generated by TGR has become the backbone for east and south China. According to the report of the China Yangtze Power Co. Ltd. (http://cypc.com.cn/CH/contents/791/98828.html), up to 24:00 31 December 2014, the annual power generation of TGR in 2014 reached 98.8 billion $\mathrm{kWh}$, creating a new world record for power generation by a single hydropower station. This has brought the total power generation of TGR to over 800 billion $\mathrm{kWh}$ (http://news.xinhuanet.com/fortune/2014-12/14/c $1113636328 . h t m$ ), equivalent to a reduction of about 0.4 billion tons of coal consumption, and emissions reductions of 0.8 billion tons of $\mathrm{CO}_{2}$ and 8 million tons of $\mathrm{SO}_{2}$.

3.2.4 Improve navigation capability With complex and large-scale navigation facilities consisting of a double-direction, five-step ship lock, with a total water head of $113 \mathrm{~m}$, as well as a large ship lift that can lift ships of 3000 tons, TGR has significantly improved navigation conditions for $600 \mathrm{~km}$ of the mainstream and $500 \mathrm{~km}$ of tributaries upstream of TGR, and 
submerged 130 shallow places, so reducing navigation costs by $36 \%$. The operation of TGR has improved navigation capacity from 10 million tons to 50 million tons in one direction. Such navigation capacity increase was predicted to happen by 2030 ; however this designed capacity was achieved in 2011.

\subsection{Effectiveness depends on non-engineering measures}

The effectiveness of engineering measures depends on non-engineering measures. The most important non-engineering measures are the flood early warning system, which has been widely accepted and recognized as the most effective and efficient Decision Support System (DSS). Figure 6 shows the DSS used in Changjiang River.

As shown in Fig. 6, the DSS is composed of: (a) a data acquisition system which produces real time observations of hydro-meteorological data, (b) meteorological forecasting models which produce 72-hour quantitative precipitation forecasts (QPF), and (c) hydrological and hydraulic models which produce predictions and scenario analysis results. Provided with all this information, during the consultation meeting, and in coordination and consultation with stakeholders such as electricity companies, local administrative government offices, navigation departments and the public, decisions on which measure should be taken, and how, are made and implemented. Figure 7 shows an example of how the TGR operated during the big flood period of July 2010.

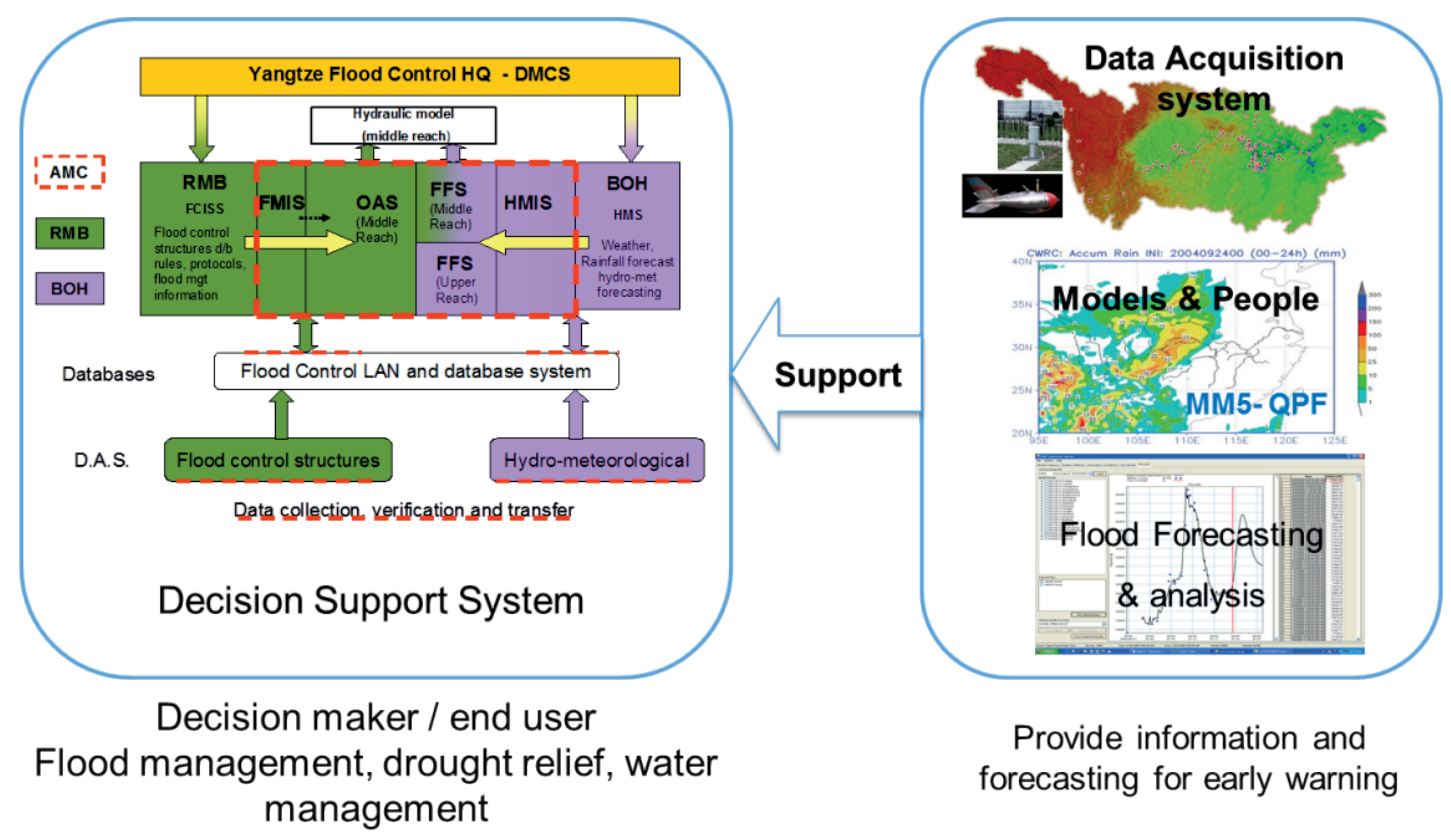

Fig. 6 Non-engineering measure of hydro-meteorological forecasting as decision support for flood and water resources management.

As shown in Fig. 7, in July 2010, the flood forecasting provided strong support to mitigate the flood risk for the downstream using the TGR. The maximum flood discharge reached $70000 \mathrm{~m}^{3} / \mathrm{s}$ (20 July 2010), which had been predicted 3 days in advance. After gradually increasing the discharge release from the reservoir from $25000 \mathrm{~m}^{3} / \mathrm{s}$ to $32000 \mathrm{~m}^{3} / \mathrm{s}$, on 17 July when a 70000 $\mathrm{m}^{3} / \mathrm{s}$ inflow peak was predicted, the decision was made to increase the discharge to $40000 \mathrm{~m}^{3} / \mathrm{s}$ from the reservoir starting from the night of $18 \mathrm{July}$. The operation stored $26.43 \mathrm{billion} \mathrm{m}^{3}$ of flood water in the reservoir, resulting in a maximum reservoir water level of $161.02 \mathrm{~m}$. This reduced water levels and flood risk of the downstream area effectively: levels were reduced by $0.88 \mathrm{~m}$ and $0.79 \mathrm{~m}$ for Chenglingji and Wuhan gauge stations, respectively. Hence, operation of the TGR successfully mitigated flood risk for the downstream area. 


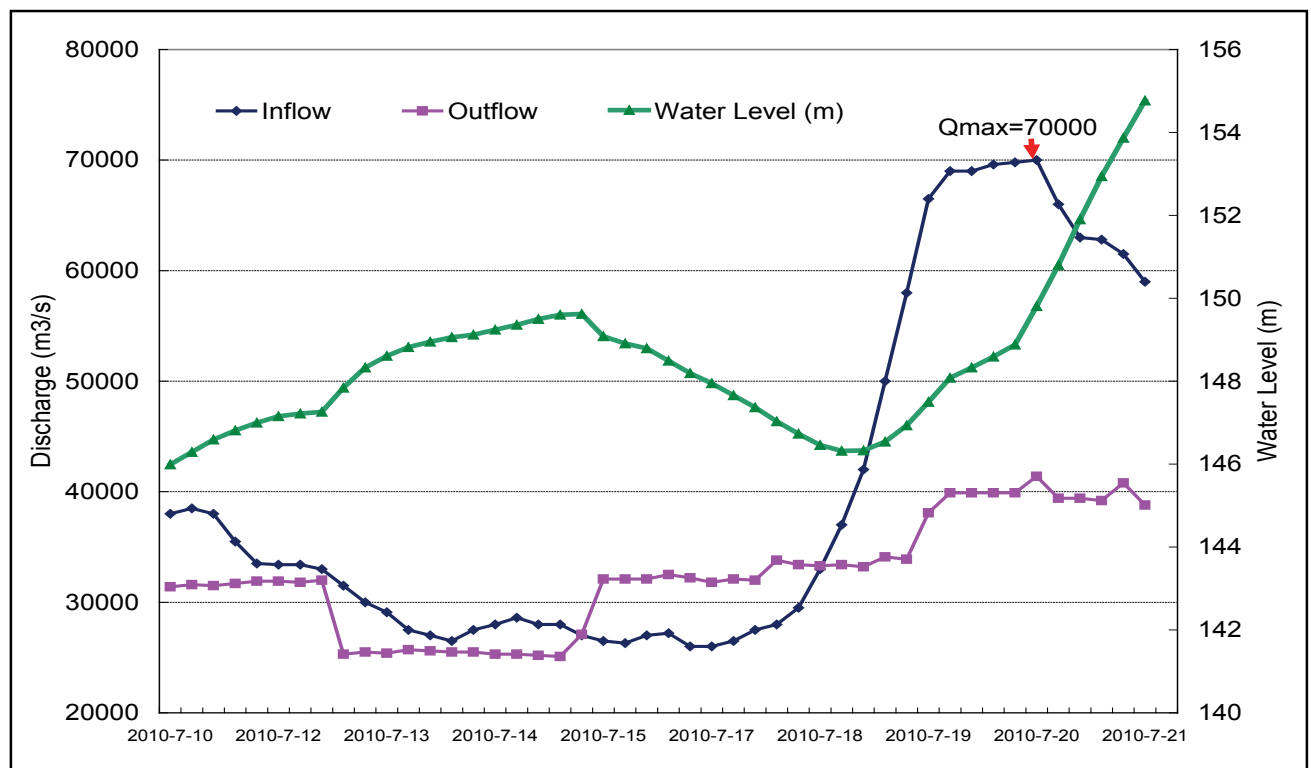

Fig. 7 Hydrograph of TGR operation for flood management in July 2010.

\section{CHANGES AND CHALLENGES CAUSED BY ENGINEERING MEASURES}

\subsection{Implementation of engineering measures causes changes of the river system}

Since it came into operation in June 2003, and especially since it was put into experimental operation for long-term regulation, i.e. to impound water up to $175 \mathrm{~m}$ after the flooding season and then drop to $145 \mathrm{~m}$ before the following flood season, TGR operation has caused increasing changes to the river system, especially in the downstream area. Observations show that, from October 2002 to October 2012, in the river reach between Yichang and Zhicheng, which is immediately downstream of the TGR dam, erosion has caused on average $3.8 \mathrm{~m}$ deepening of the river bottom (Fig. 8). Such change might cause low water levels during the dry season, which might affect water intakes set along the river channel. Thus, care must be taken to mitigate such negative impacts.

\subsection{Demands of increasing socio-economic development changes}

The longer the TGR is in operation, the more demands of its functionality may rise. For instance, to deal with changes caused to fish in the downstream area, large amounts of observation and research have been carried out. As a result, to reinstall fish spawning conditions before summer time for the four major types of commercially-economic fish, a particular ecological operation rule was developed, i.e. to generate artificial floods when the water temperature is appropriate to stimulate the fish to spawn. The observations show that the operation rule is effective, but care should be taken as it is highly sensitive to water temperature. Similar research and experiments have been conducted to deal with sediment issues. In addition, TGR has improved navigation capacity from 10 million to 50 million tons, which was planned to happen in 2030 but has already happened in 2011. Such escalatory development would require even more rapid upgrading to the reservoir regulation and perhaps even the construction itself, if it continues.

In summary, it should be noted that, although regulations and principles were provided during the design and early operation stage of the project, these could not satisfy the operational needs of real-time management. Thus, with all the changes introduced by, and brought to the operation of TGR, more comprehensive and in-depth studies and field observations and experiments (for validation purposes) are needed. 


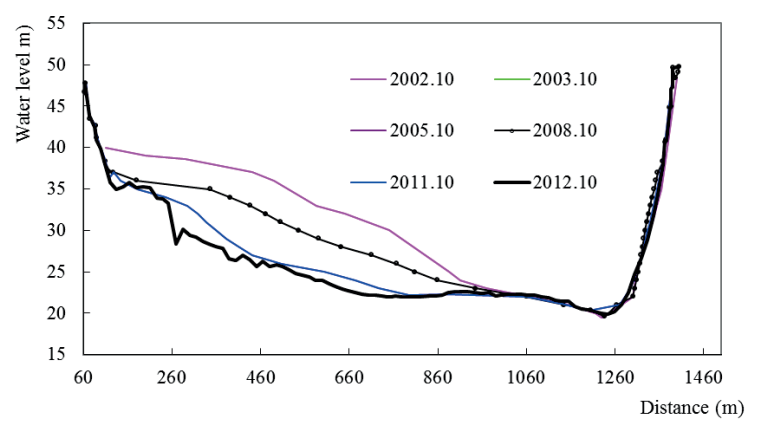

Zhicheng

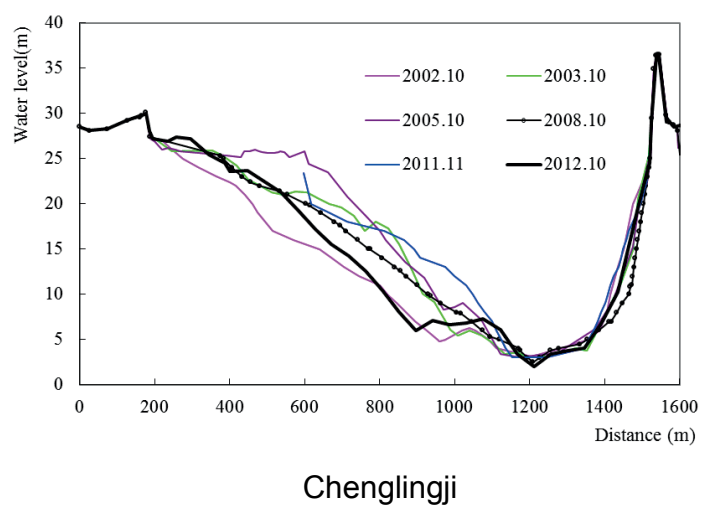

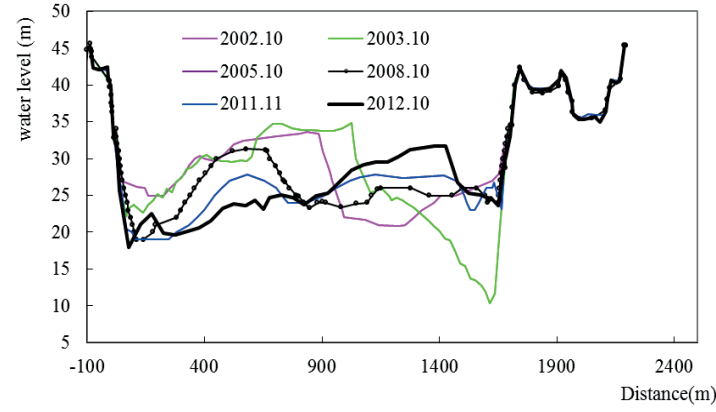

Shashi

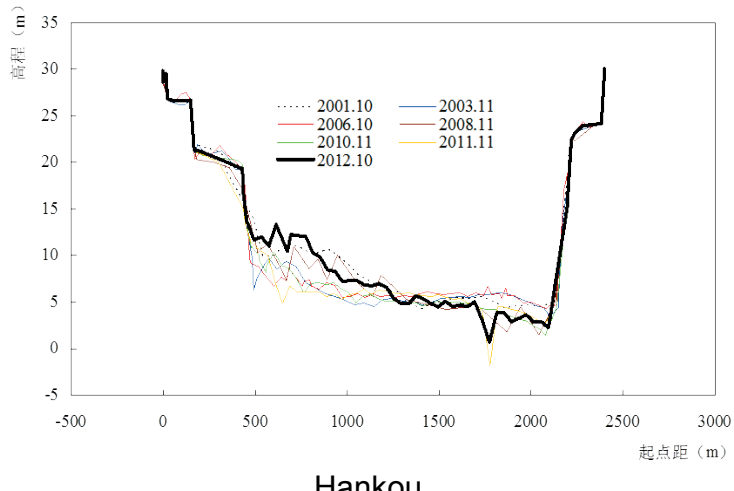

Fig. 8 Erosion at downstream areas of TGR during 2002-2012 shows a growing change with time and downstream-wards.

\subsection{More newly built reservoirs increased the complexity of river management}

Another huge impact and change is the number of new reservoirs built recently in the upper rivers, which will require management of at least 100 billion $\mathrm{m}^{3}$ of reservoir storage/water volume. In 2015, all big reservoirs, such as Xiluodu, Xiangjiaba and Tingzikou, will come into full operation, which requires urgent development of further operation rules in an integrated manner, as well as an integrated and participatory management mechanism/system.

\section{CONCLUSIONS AND RECOMMENDATIONS}

The planning and implementation practices of Changiiang River show that integrated river basin planning is a key for appropriate water and basin management. Planning for Changjiang River consists of various aspects such as flood management, integrated water utilization, water and environment protection and management. During the past decades, systematic engineering measures for flood control, water utilization, etc., were developed and implemented in Changjiang River, and have shown great benefits in dealing with water issues including flood control and water supply.

Operation of a representative engineering measure, the Three Gorges Reservoir, is presented. TGR has significantly contributed to socio-economic development through mitigating flood risk effectively, compensating water resources of the downstream area in the dry season, generating huge amounts of power and greatly improved the navigation capacity of the river. In addition, the operation of TGR shows that the usefulness and effectiveness of engineering measures depends largely on non-engineering measures, such as the operation rules and flood forecasting systems.

However, it should be noted that operation of engineering measures causes changes to the river system and human demands. Observations show that the operation of TGR has caused increasing changes to the river in downstream areas, and people have developed more and more interests and needs which require exploration of the functionality of TGR. Efforts shall be made to observe and study those changes and search for solutions to, on the one hand, mitigate its negative impacts, and on the other hand, to make better and better use of the engineering measures. 


\section{REFERENCES}

CISPDR (2005) Feasibility study report of the middle route of water diversion from South to North China (Phase I). Internal report, No. S71F05-032X, Changjiang Institute of Survey Planning Design and Research (CISPDR).

CISPDR (2014) Impact to the probability of using retention zones at downstream due to operation of TGR. Internal Research Report, Changiiang Institute of Survey Planning Design and Research (CISPDR).

CWRC (2003) Basic information for flood management of Changjiang River. Internal work report, Changjiang Water Resources Commission (CWRC).

CWRC (2009) Optimized regulation rules for the operation of Three Gorges Reservoir. Internal report, approved in 2009 by the central government of China, developed by Changjiang Water Resources Commission (CWRC), the Ministry of Water Resources, China.

CWRC (2011) Changjiang river basin planning. Internal Report, Changjiang Water Resources Commission.

CWRC, PRWRC (2012) Planning report of short-term construction of key water source project of five provinces of South-West China (Autonomous regions and municipalities). Internal report, Changjiang Water Resources Commission (CWRC), Peal River Water Resources Commission (PRWRC), March, 2012. 